\title{
Compact Design of Circularly Polarized Antenna with Vertical Slotted Ground for RFID Reader Application
}

\author{
Hesheng Cheng, ${ }^{1}$ Jin Zhang, ${ }^{2}$ Hexia Cheng, ${ }^{3}$ and Qunli Zhao ${ }^{1}$ \\ ${ }^{1}$ College of Computer Science, Hefei Normal University, Hefei, China \\ ${ }^{2}$ School of Electronic and Information Engineering, Jinling Institute of Technology, Nanjing, China \\ ${ }^{3}$ College of Computer \& Information, Anqing Normal University, Anqing, China
}

Correspondence should be addressed to Hesheng Cheng; chenghesheng238@126.com

Received 7 March 2017; Revised 17 August 2017; Accepted 6 September 2017; Published 3 December 2017

Academic Editor: Jit S. Mandeep

Copyright (C) 2017 Hesheng Cheng et al. This is an open access article distributed under the Creative Commons Attribution License, which permits unrestricted use, distribution, and reproduction in any medium, provided the original work is properly cited.

\begin{abstract}
A novel compact circular polarization (CP) microstrip antenna is proposed for UHF ultrahigh frequency (UHF) radio frequency identification (RFID) reader applications. The proposed antenna is composed of a corner truncated square-ring radiating patch on a substrate and a vertical slotted ground surrounding four sides of the antenna. A new feeding scheme is designed from flexible impedance matching techniques. The impedance bandwidths for $S_{11}<-10 \mathrm{~dB}$ and $3 \mathrm{~dB}$ axial ratio (AR) bandwidth are $12.1 \%$ (794.5-896.5 MHz) and 2.5\% (833.5-854.5 MHz), respectively.
\end{abstract}

\section{Introduction}

RFID reader system in the UHF band has developed rapidly due to its numerous application [1]. The reader antenna is one of the important components in the RFID reader system, which has been designed with CP radiation for reducing the loss caused by the multipath effects between a reader and the tag. Circularly polarized reader antenna is useful in practice when tag antenna system is in rotating motion or when its respective orientation cannot be ensured

Total frequency span of $840-960 \mathrm{MHz}$ is used for UHF RFID systems worldwide. In China, RFID and other lowpower radio applications are regulated, allowing RFID operation with somewhat complex band restrictions from 840 to $845 \mathrm{MHz}$ or 920 to $925 \mathrm{MHz}$. In this paper, a compact circularly polarized antenna for handheld UHF RFID reader operates at the bands of 840-845 MHz. Design of a compact CP microstrip antenna is attractive for handheld/portable device application. Some minimized CP antennas have been reported in literatures [2-4]. Reference [2] demonstrated that the size requirement of square-ring microstrip antenna is smaller than that of conventional design using a square patch. However, the antenna gains and $3 \mathrm{~dB}$ axial ratio bandwidth for such compact circular polarization (CP) designs are also decreased, which is a severe limitation for practical applications of such antennas. Reference [3] proposed antenna with vertical ground surrounding four sides of the antenna to further reduce size and obtain high gain; however the antenna's cost is high for using a highpermittivity substrate. Reference [4] used foam instead of high-permittivity substrate to obtain the merit of low cost. The antenna in [5] is composed of two corner truncated patches and a suspended microstrip line with open-circuited termination. The main patch is fed by four probes which are sequentially connected to the suspended microstrip feed line. Reference [6] designed a circularly polarized RFID antenna using a horizontal bend line feed technology. The antenna in [7] is composed of two patches. The main patch which is truncated to generate $\mathrm{CP}$ radiation is fed directly by the SMA connector oriented in the same plane via the vertical part of the L-shaped ground. The parasitic patch used to enhance the bandwidth is placed at the same layer of the main patch. References [5-7] realized the UHF RFID antenna but its size is too large to facilitate the practical application. References [8,9] developed a small circularly polarized RFID antenna, but the antenna bandwidth is so narrow that it cannot meet the requirements of UHF RFID applications. 


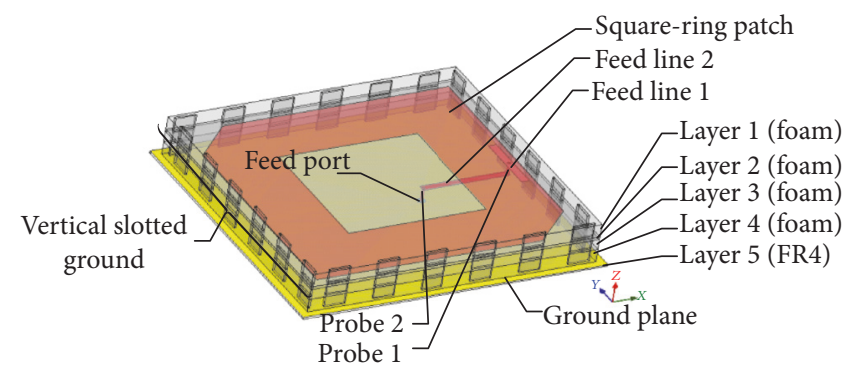

(a)

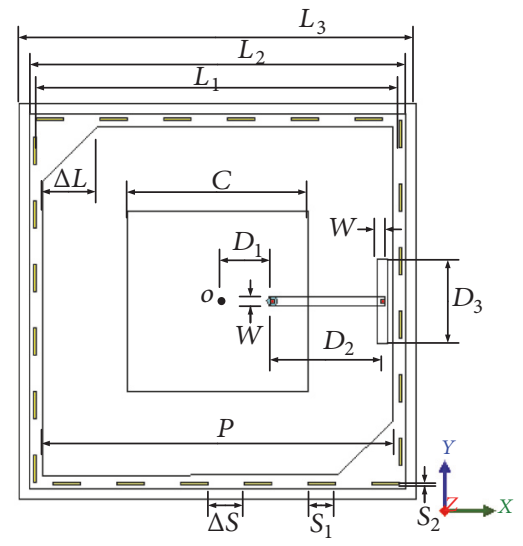

(b)

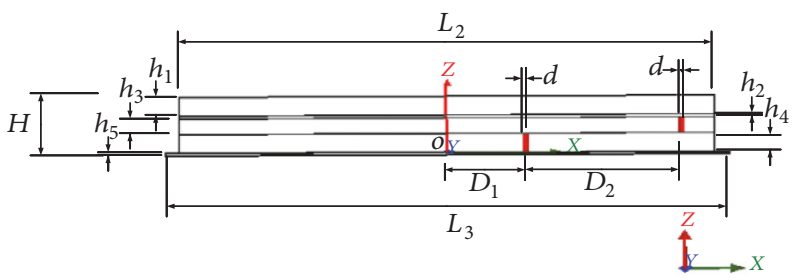

(c)

FIGURE 1: Geometry of proposed antenna. (a) 3D structure; (b) top view; (c) side view (hide vertical slotted ground). $H$ is the total height of the five layers, $H=h_{1}+h_{2}+h_{3}+h_{4}+h_{5}$, and dielectric constant $\varepsilon_{e}=4.4$.

TABLE 1: Values of proposed antenna parameters.

\begin{tabular}{lccc}
\hline$L_{1}=106.5 \mathrm{~mm}$ & $\Delta L=15.5 \mathrm{~mm}$ & $S_{1}=8 \mathrm{~mm}$ & $h_{3}=5 \mathrm{~mm}$ \\
$L_{2}=110.5 \mathrm{~mm}$ & $D_{1}=15.4 \mathrm{~mm}$ & $S_{2}=0.8 \mathrm{~mm}$ & $h_{4}=6 \mathrm{~mm}$ \\
$L_{3}=116.5 \mathrm{~mm}$ & $D_{2}=47 \mathrm{~mm}$ & $\Delta S=18.7 \mathrm{~mm}$ & $h_{5}=0.8 \mathrm{~mm}$ \\
$P=102.5 \mathrm{~mm}$ & $D_{3}=25 \mathrm{~mm}$ & $h_{1}=6 \mathrm{~mm}$ & $d=0.6 \mathrm{~mm}$ \\
$C=53 \mathrm{~mm}$ & $W=3 \mathrm{~mm}$ & $h_{2}=1 \mathrm{~mm}$ & $H=12 \mathrm{~mm}$ \\
\hline
\end{tabular}

In this letter, a new compact CP and low cost design of a square-ring microstrip antenna with a vertical slotted ground plane are proposed. It is found that, by properly embedding a group of slots in the finite vertical ground plane surrounding four sides of the square-ring microstrip antenna, the lowering of the resonant frequency of the antenna can be obtained. Moreover, the $3 \mathrm{~dB}$ axial ratio bandwidth of the proposed scheme is greater than that of the above-mentioned design [2-4].

\section{Antenna Structure}

Figure 1 shows the proposed CP antenna which is formed from five layers. The parameters of the optimized antenna are shown in Table 1 . Layer 1 is a foam plate $\left(L_{1} \times L_{1}=106.5 \times\right.$ $\left.106.5 \mathrm{~mm}^{2}\right)$; the radiating corner truncated square-ring patch $\left(P \times P=102.5 \times 102.5 \mathrm{~mm}^{2}\right)$ is mounted on layer 2 . The corners truncated patch is to achieve circular polarization. In the center of patch, one square slot is taken in order to achieve miniaturization of the antenna. Feed line 1 is printed on layer 3; by the same token, feed line 2 is printed on the layer $4\left(L_{2} \times L_{2}=110.5 \times 110.5 \mathrm{~mm}^{2}\right)$. Feed line 1 connects the radiating patch by capacitive coupled technique. Feed line 1 is linked to feed 2 with probe 1 embedded in layer 3; similarly, feed port which is in layer 4 is attached to feed line 2 with probe 2. Layer 5 is a ground plane which is FR4 plate covered with copper sheet. Moreover, feed lines 1 and 2 are designed to $Z$ shape in order to achieve $50 \Omega$ impedance matching. The Z-shaped and capacitive coupled structure can obtain flexible impedance matching. To further reduce size, vertical slotted ground, which is employed by rectangular parallelepiped metallic via holes for easily fabricated, surrounding four sides of the antenna is proposed. Using a dielectric substrate with a high dielectric constant, the size of the antenna can be reduced. The dielectric constant is $\varepsilon_{e}=4.4$ in this paper.

\section{Simulation and Discussion}

The simulation CP axial ratio and return loss parameters of the proposed antenna are displayed in Figure 2. The 
TABLE 2: Performance of proposed and reference antennas.

\begin{tabular}{lcccccc}
\hline $\begin{array}{l}\text { Kinds of } \\
\text { antenna }\end{array}$ & $\begin{array}{c}f_{c} \\
(\mathrm{MHz})\end{array}$ & $\begin{array}{c}\text { Peak directivity } \\
(\mathrm{dB})\end{array}$ & $\begin{array}{c}\text { Peak gain } \\
(\mathrm{dBi})\end{array}$ & $\begin{array}{c}\text { Radiation } \\
\text { efficiency } \\
(\%)\end{array}$ & $\begin{array}{c}\text { F/B } \\
(\mathrm{dB})\end{array}$ & $\begin{array}{c}\text { BW1 } \\
(\%)\end{array}$ \\
\hline $\begin{array}{l}\text { Proposed } \\
\text { antenna }\end{array}$ & 842.5 & 4.1 & 3.8 & 92.8 & 15.0 & 12.1 \\
Antenna 1 & 928.8 & 5.7 & 4.6 & 77.8 & 10.5 & 2.5 \\
Antenna 2 & 1034.3 & 5.3 & 4.9 & 89.3 & 3.8 & 0.65 \\
Antenna 3 & 1215.2 & 6.5 & 6.4 & 97.0 & 5.7 & 1.4 \\
\hline
\end{tabular}

$f_{c}$ : centre frequency of BW2; F/B: front to back ratio; BW1: $10 \mathrm{~dB}$ return loss impedance bandwidth; BW2: $3 \mathrm{~dB}$ axial ratio CP bandwidth.

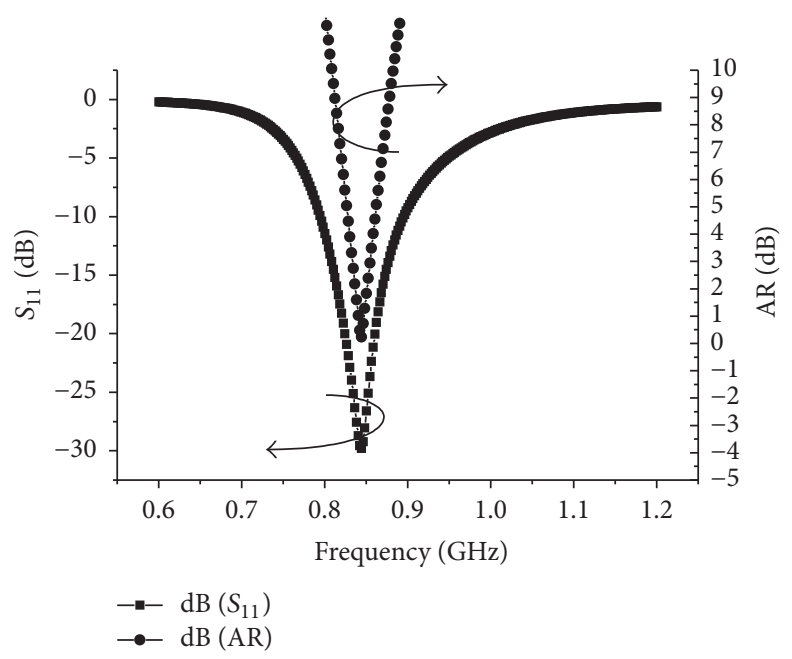

FIgURE 2: Axial ratio and return loss of the proposed antenna.

simulation results show that the bandwidth of CP and return loss operation, which are defined by $3 \mathrm{~dB}$ axial ration and $-10 \mathrm{~dB}$ return loss, are about $21 \mathrm{MHz}(2.5 \%$ at $842.5 \mathrm{MHz})$ and $102 \mathrm{MHz}(12.1 \%$ at $842.5 \mathrm{MHz})$, respectively, at the centered $842.5 \mathrm{MHz}$, covering the bandwidth of $840-845 \mathrm{MHz}$. The radiation patterns of two principal planes at $842.5 \mathrm{MHz}$ are plotted in Figure 3. The gain of $3.8 \mathrm{dBi}$ is obtained at $842.5 \mathrm{MHz}$, good right-hand $\mathrm{CP}$ radiation is observed, and the $\mathrm{CP}$ isolation is more than $26 \mathrm{~dB}$. The half-power beam width (HPBW) is $99^{\circ}$ and $98^{\circ}$, respectively, in $x o z$ plane and yoz plane. Due to the vertical slotted ground the front-toback ratio $(\mathrm{F} / \mathrm{B})$ reaches $15 \mathrm{~dB}$.

At the same sizes of radiating patch (parameters $P$ ) and height of substrate (parameter $H$ ), another three antenna prototypes are implemented for comparing with the proposed antenna: antenna with vertical ground and squarering patch (antenna 1), antenna without vertical ground and with square-ring patch (antenna 2), and conventional corner truncated square patch antenna [5] (antenna 3). The simulated results of the axial ratio and return loss are shown in Figure 4. From the results obtained, it is clearly seen that the center frequency of the proposed antenna is about $9 \%$ lower than antenna 1, about 19\% lower than antenna 2, and about $31 \%$ lower than antenna 3. That corresponds to an antenna size reduction of about $10 \%, 23 \%$, and $44 \%$ for the proposed antenna at a fixed frequency, respectively. This characteristic suggests that the constructed vertical slotted ground surrounding square-ring patch achieves good effect in miniaturization.

The corresponding simulated data of the proposed antenna and the other reference antennas are given in Table 2 for comparison. It is first noted that the impedance bandwidth and the CP bandwidth of the proposed antenna are larger than antenna 1 and antenna 2 and approximate to antenna 3. As known, the quality factor of the microstrip antenna dropped with operating frequency risen. Therefore, comparing proposed antenna with the reference antennas, it is found that embedded slot in vertical ground can effectively widen antenna bandwidth. Moreover, the F/B reaches $15 \mathrm{~dB}$ of proposed antenna, larger than any other references. It is also noted that, owing to the lowering of the resonant frequency which results in a decrease in peak directivity of the proposed antenna, the peak gain is decreased.

\section{Conclusions}

A novel compact circularly polarized square-ring microstrip antenna with vertical slotted ground for UHF RFID has been successfully implemented, which is designed as Z-shaped and capacitive coupled structure. The proposed design can have a size reduction of about 10\% (contrasting with [2]), 23\% (contrasting with [3]), and 44\% (contrasting with [4]); moreover, the substrate material is foam and FR4, in order to be low cost. Furthermore, the impedance bandwidths for $S_{11}<-10 \mathrm{~dB}$ 

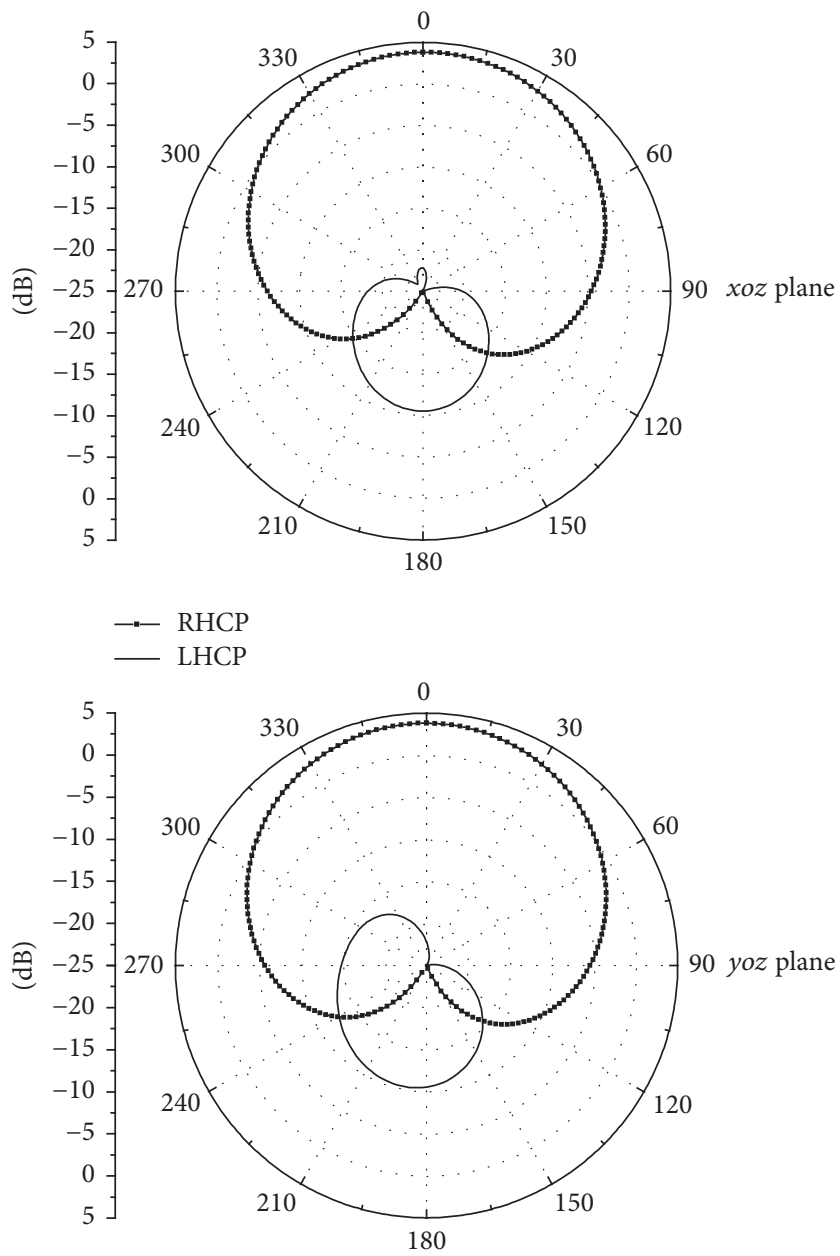

$\rightarrow$ RHCP

- LHCP

FIGURE 3: Radiation pattern of the proposed antenna.

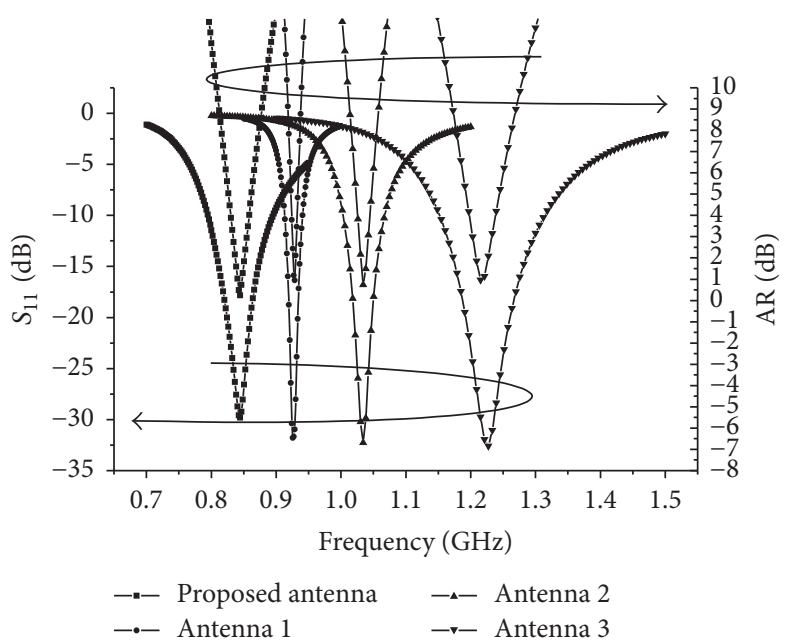

FIGURE 4: Simulated return losses and axial ratio of the proposed antenna and reference antennas. 
and $3 \mathrm{~dB}$ AR bandwidth are 12.1\% (794.5-896.5 MHz) and $2.5 \%(833.5-854.5 \mathrm{MHz})$, respectively. Due to the use of a vertical trench structure, the antenna achieves up to $15 \mathrm{~dB}$ of front-to-back ratio at $845.2 \mathrm{MHz}$.

\section{Conflicts of Interest}

The authors declare that they have no conflicts of interest.

\section{Acknowledgments}

This research work was supported by Educational Commission of Anhui Province of China (KJ2016A585, 1708085QF157, gxyq2017050, and 2015jyxm271).

\section{References}

[1] K. Finkenzeller, RFID Handbook, John Wiley \& Sons, New York, NY, USA, 2nd edition, 2003.

[2] W.-S. Chen, C.-K. Wu, and K.-L. Wong, "Single-feed squarering microstrip antenna with truncated corners for compact circular polarisation operation," IEEE Electronics Letters, vol. 34, no. 11, pp. 1045-1047, 1998.

[3] S. Kim, H. Park, D. Lee, and J. Choi, "A novel design of an UHF RFID reader antenna for PDA," in Proceedings of the 2006 AsiaPacific Microwave Conference, APMC, pp. 1471-1473, December 2006.

[4] Z. Wang, S. Fang, and S. Fu, "A low cost miniaturized circularly polarized antenna for UHF radio frequency identification reader applications," Microwave and Optical Technology Letters, vol. 51, no. 10, pp. 2382-2384, 2009.

[5] N. Z. Chen, X. Qing, and L. C. Hang, "A universal UHF RFID reader Antenna," IEEE Transactions on Microwave Theory \& Techniques, vol. 57, no. 5, pp. 1275-1282, 2009.

[6] Z. Wang, S. Fang, S. Fu, and S. Jia, "Single-fed broadband circularly polarized stacked patch antenna with horizontally meandered strip for universal UHF RFID applications," IEEE Transactions on Microwave Theory and Techniques, vol. 59, no. 4, pp. 1066-1073, 2011.

[7] Y. Pan, L. Zheng, H. J. Liu, J. Y. Wang, and R. L. Li, "Directly-fed single-layer wideband RFID reader antenna," IEEE Electronics Letters, vol. 48, no. 11, pp. 607-608, 2012.

[8] C.-Y. Sim and C.-J. Chi, "A slot loaded circularly polarized patch antenna for UHF RFID reader," IEEE Transactions on Antennas and Propagation, vol. 60, no. 10, pp. 4516-4521, 2012.

[9] M. K. Chang, J. R. Lin, and C. I. Deng, "A novel design of a microstrip-fed shorted square-ring slot antenna for circular polarization," Microwave \& Optical Technology Letters, vol. 49, no. 7, pp. 1684-1687, 2010. 


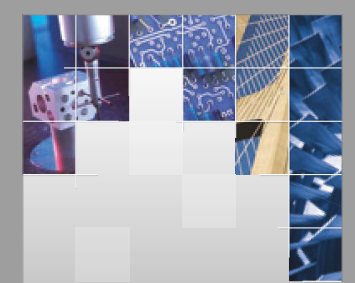

\section{Enfincering}
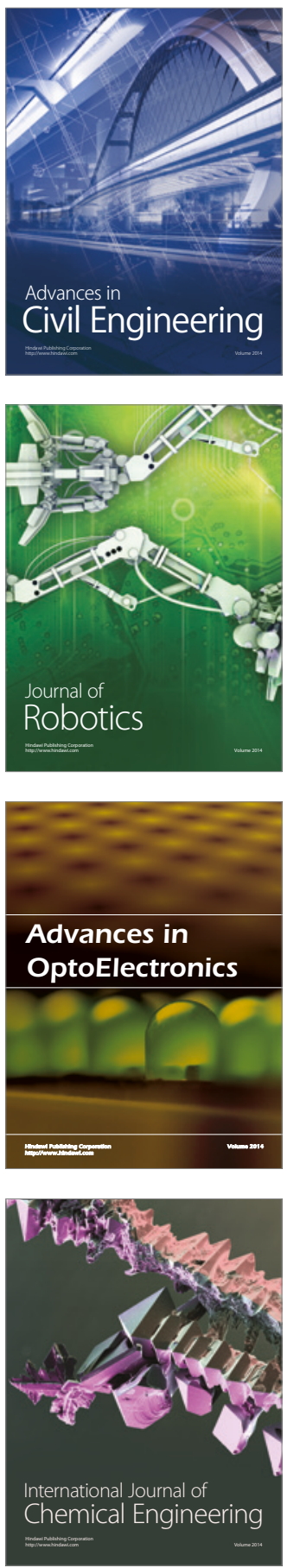

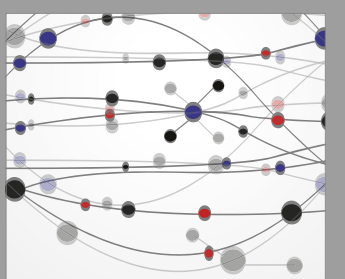

The Scientific World Journal

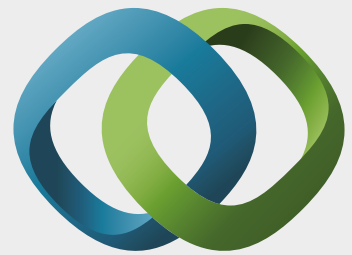

\section{Hindawi}

Submit your manuscripts at

https://www.hindawi.com
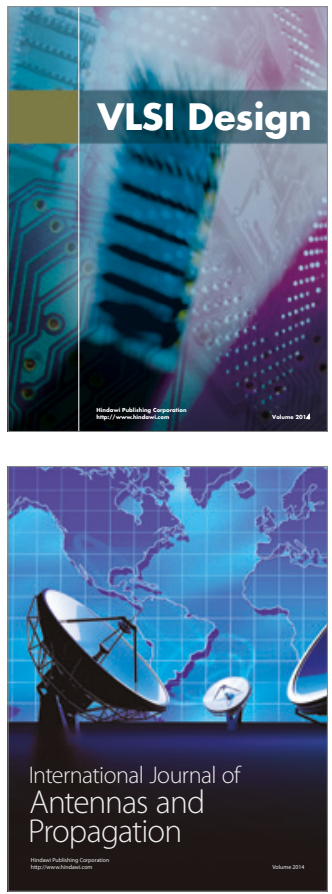

\section{Rotating}

Machinery
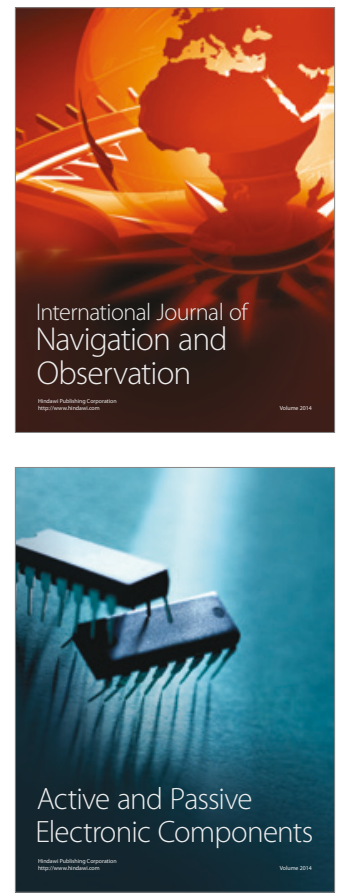
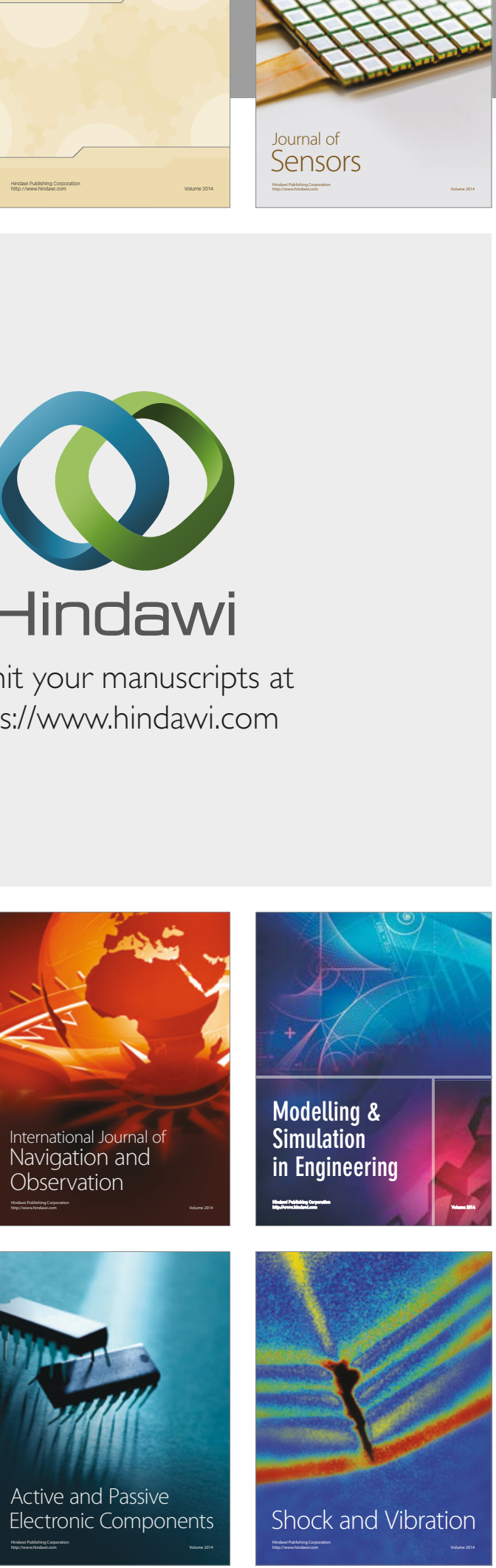
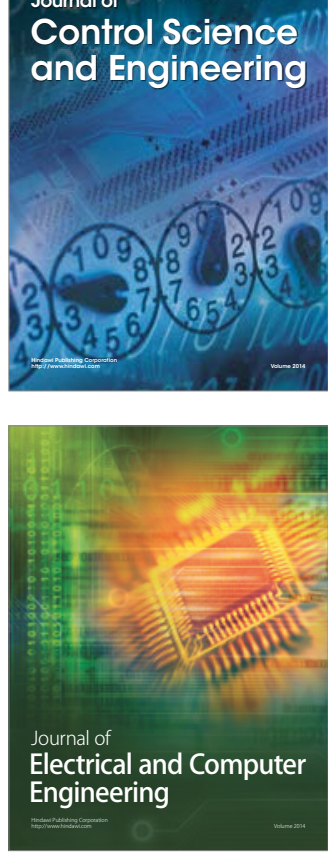

Distributed

Journal of

Control Science

and Engineering
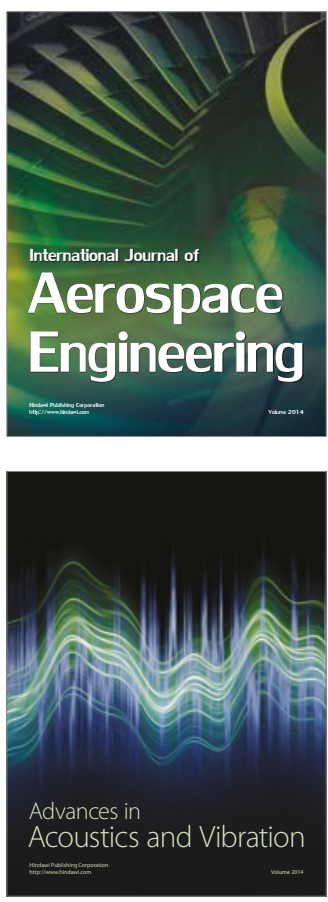

Sensor Networks 